\title{
La cuestión educativa en las prácticas museales*
}

The Educational Issue in Museum Practices A questão educativa nas práticas museológicas

Rocío del Pilar Méndez Suárez**

\section{Para citar este artículo}

Méndez-Suárez, R. (2021). La cuestión educativa en las prácticas museales. Pedagogía y Saberes, (54). https// doi.org/10.17227/pys.num54-11393

* Artículo de reflexión en el marco del seminario Conceptos fundamentales de la pedagogía (2019-II) del Doctorado Interinstitucional en Educación de la Universidad Pedagógica Nacional, orientado por los doctores Carlos Ernesto Noguera Ramírez y David Andrés Rubio Gaviria. Hace parte del proyecto de investigación doctoral sobre "Educación y museos", en tutoría con el doctor Alfonso Torres Carrillo.

** Antropóloga y magíster en Historia de la Universidad Nacional de Colombia. Docente de Ciencias Sociales, IED Ricardo González (Subachoque, Cundinamarca). Estudiante del Doctorado Interinstitucional en Educación, Universidad Pedagógica Nacional.

Correo electrónico: rdmendezs@upn.edu.co

Código Orcid: https://orcid.org/0000-0003-2211-911X 


\title{
Resumen
}

El presente artículo cuestiona el lugar de lo educativo en lo museal, tanto en su concreción institucional como en su dimensión de práctica cultural, y establece su relevancia como objeto de investigación. A partir de la indagación por la emergencia de la función educativa de manera explícita en el museo contemporáneo, se rastrea su trayectoria como institución, en particular durante el siglo xx, la progresiva demanda social por lo educativo y su cercanía a las manifestaciones de escolarización. Teniendo en cuenta el marco conceptual que permite advertir los matices entre una u otra denominación en el ámbito educativo, se realiza una aproximación al carácter y propósito del quehacer museal, advirtiéndose su tendencia hacia el aprendizaje. Esto se hace evidente en la actual discusión sobre la forma de definir al museo, en la que se pone en sospecha el término "educación", lo que también sucede desde el denominado "giro educativo" en el sector cultural. De esta manera, se esboza cómo la institución museal ha transitado desde los ideales de la educación permanente a los del aprendizaje permanente, continuo o a lo largo de la vida. Asimismo, se propone la idea de "transmisión" como mecanismo que vehicula la educación museal hacia lo cultural, al igual que permite dilucidar la tensión educativa que afronta el museo entre la comunicación de masas y la escolarización, en particular con respecto a la formación de ciudadanía.

\section{Palabras clave}

museos; prácticas educativas; educación permanente; aprendizaje; educación patrimonial

\begin{abstract}
This article questions the place of education in the museum, both in its institutional concreteness and in its dimension of cultural practice, and establishes its relevance as an object of research. From the investigation of the emergence of the educational function in an explicit way in the contemporary museum, we trace its trajectory as an institution, particularly during the 20th century, the progressive social demand for education, and its proximity to the manifestations of schooling. Taking into account the conceptual framework that allows us to notice the nuances between one or another denomination in the educational field, an approximation to the character and purpose of the museum's work is made, noting its tendency towards learning. This becomes evident in the current discussion on how to define the museum, in which the term "education" is put under suspicion, which also happens from the so-called "educational turn" in the cultural sector. In this way, it outlines how the museum institution has moved from the ideals of lifelong education to those of lifelong or continuous learning. It also proposes the idea of "transmission" as a mechanism that connects museum education to the cultural sector, as well as elucidating the educational tension that the museum faces between mass communication and schooling, particularly concerning the formation of citizenship.
\end{abstract}

\section{Keywords}

museums; educational practices; lifelong education; learning; heritage education

\section{Resumo}

Este artigo questiona o lugar da educação no museu, tanto na sua concretude institucional como na sua dimensão de prática cultural, e estabelece a sua relevância como objeto de investigação. A partir da investigação da emergência da função educativa explicitamente no museu contemporâneo, traçamos a sua trajetória como instituição, particularmente durante o século Xx, a progressiva procura social de educação e a sua proximidade às manifestações da escolaridade. Levando em conta o quadro conceptual que nos permite ver as nuances entre uma ou outra denominação no campo educacional, é feita uma abordagem ao carácter e à finalidade do trabalho do museu, notando a sua tendência para a aprendizagem. Isto é evidente na atual discussão sobre como definir o museu, em que o termo "educação" é colocado sob suspeita, o que é também o caso da chamada "virada educacional" no sector cultural. Isto descreve como a instituição do museu passou dos ideais da educação contínua para os da aprendizagem permanente, contínua ou ao longo da vida. Propõe também a ideia de "transmissão" como mecanismo de transporte da educação museológica para o sector cultural, bem como a clarificação da tensão educacional enfrentada pelo museu entre a comunicação de massas e a escolarização, particularmente no que diz respeito à formação da cidadania.

\section{Palavras-chave}




\section{Introducción}

Los museos contemporáneos hacen explícitas determinadas relaciones y dinámicas que se enuncian como "educativas". Si bien estos espacios han operado en articulación con la escuela, existe una pugna por su autonomía, para no ser catalogados como "un aula más" ${ }^{11}$ convertirse en una alternativa a la educación escolarizada. Para comprender ese estado actual del museo, es necesaria una aproximación a su trayectoria como institución, que da cuenta de discusiones clave alrededor de conceptos fundamentales en el ámbito educativo, en particular con respecto a la educación permanente como contexto a partir del cual se hace énfasis en el rol educativo de los museos, el método y la didáctica que pretenden ser diferentes en el museo con respecto a la escuela, la reconfiguración del discurso y las prácticas museales en respuesta a las demandas del aprendizaje continuo, y el lugar de la transmisión en la educación patrimonial. Pero, ¿podemos denominar "educación" a aquello que acontece en las prácticas museales? Es la cuestión que se explora en el presente texto.

\section{Trayectoria de la institución museal en el contexto de la educación permanente}

En sus inicios el museo no era concebido como institución educativa, por lo que se debe realizar un breve seguimiento a su dinámica histórica, social y disciplinar para identificar la emergencia de las condiciones que lo erigieron como tal. Este recorrido comienza en el siglo XVIII, en las sociedades inmersas en la Revolución industrial, donde el imperativo de la dimensión económica tiene como eje el concepto de trabajo, y por ello resultan fecundas las ideas precursoras sobre la relación entre educación y formación permanente (Comenio, siglo XVII; Condorcet, siglo XVIII; Dewey y Bachelard, siglos XIX y XX). En ese contexto, los museos técnicos se mencionan como ejemplos de realizaciones concretas originadas en la preocupación de la época "por difundir ampliamente los conocimientos científicos y técnicos" (Léon, 1986, p. 29).

1 Entre 1989 y el 2000, la artista María Elena Ronderos y el Departamento de Educación del Museo de Arte de la Universidad Nacional de Colombia desarrollaron una investigación pedagógica y participativa que se denominó “El museo, un aula más en la vida de los escolares", que impactó en la concepción de la educación artística en los niveles de básica y media (Moreno Moya, 2016). Como se desarrollará más adelante, la posibilidad de escolarización del museo es vista con recelo por algunos sectores de profesionales de museos en la actualidad.
Para el último tercio del siglo XIX, el tiempo libre se convierte en una necesidad, que se fue colmando de iniciativas culturales para su aprovechamiento (Léon, 1986). "El fenómeno complejo del ocio" (Faure et ál., 1973, p. 172) se torna un espacio de tiempo en el que se interceptan la vida pública y la privada, un derecho para el desarrollo de los intereses personales y, a su vez, fuente de transformación de los valores en el trabajo, la política, la fe y la familia (Dumazedier, citado en Faure et ál., 1973). En Estados Unidos, durante el periodo de 1900 a 1930, se evidencia un desarrollo de prácticas y programas educativos en los museos, que como institución educativa "se debía a las necesidades y deseos de la comunidad a la cual servía" y a las perspectivas de búsqueda de equilibrio entre la erudición y la educación (Pastor, 2004).

En el siglo Xx, en particular después de las guerras mundiales, se intensifican los llamados de atención y los esfuerzos orientados hacia la alfabetización, desde el sistema escolarizado y fuera de él. Luego de la Primera Guerra Mundial, se reitera la necesidad de una educación para adultos, universal y permanente, así como la reforma escolar y la renovación de las formas de educación popular (Léon, 1986). A partir de la segunda posguerra, estas intenciones se materializan en una mayor inversión de los presupuestos nacionales en el rubro de la educación (Faure et ál., 1973). Como denomina Pastor el apartado sobre la configuración de la educación no formal, se trata de "nuevos espacios educativos para nuevos destinatarios y necesidades formativas emergentes" (2004, p. 13), para las "categorías menos favorecidas" como lo enuncia Léon (1986, p. 42). Los ámbitos de dicha educación no formal se pueden clasificar según responda a necesidades educativas orientadas al desarrollo económico, social y cultural, político, y científico y tecnológico (Pastor, 2004). Así, el quehacer de los museos se orientaría al desarrollo sociocultural, en el que la autora identifica algunas tendencias de los cambios en los patrones culturales: mayor democratización cultural, expansión de la creencia en la rentabilidad de la inversión cultural, y acción de los medios de comunicación de masas en la uniformización y masificación de los modelos culturales.

Entre dichas tendencias son de destacar los cambios en el uso y la valoración del tiempo libre, que consisten en la ruptura con el tiempo dedicado al trabajo; la mayor valoración y necesidad de su aprovechamiento; la tendencia al individualismo; un mayor sentido lúdico y hedonístico; el incremento de la población que dispone de tiempo libre, y la aparición de grupos alternativos a la familia para compartirlo (Pastor, 2004). Ahora el foco es la población, lo que se advierte en los informes de Philip H. Coombs 
(publicados en 1968 y 1985) y de la Unesco, donde se destacan los factores que definen y condicionan la naturaleza y la manera de satisfacer las necesidades de aprendizaje, las cuales varían según la cultura y la época; dichos factores son el crecimiento demográfico y los fenómenos migratorios, la urbanización, los avances científicos y tecnológicos, los cambios sociales y económicos, y la progresiva interdependencia mundial (Pastor, 2004). De esta manera, el crecimiento demográfico en los denominados "países en vía de desarrollo" daría lugar a una mayor demanda popular por la educación básica, que superaría la oferta de los sistemas educativos formales.

La visión de museo como institución educativa fue la postura de mayor desarrollo en el siglo xx. Durante el crecimiento económico de los años sesenta, se acentúa la demanda social y educativa, tanto en el sistema escolar como en las instituciones sociales y culturales que "pueden contribuir a la mejora del nivel formativo y al bienestar de la población" (Pastor, 2004, p. 31). En la segunda mitad de esa década, la educación permanente aparece como la panacea, "uno de los medios privilegiados que permitiría resolver los grandes problemas de nuestro tiempo", que evitará la decadencia de la democracia y será el remedio a las taras del sistema escolar (Léon, 1986, p. 33). Esta tendencia parece encarnar el ideal de la formación del hombre completo (Faure et ál., 1973), asociado a las ideas de continuidad e integridad que ya se encuentran en la noción de educación de Comenio (Léon, 1986), así mismo en la posibilidad de perfectibilidad - como especie e individuo- que implica el paso del hombre natural al hombre social, en Rousseau y antes de él (Noguera, 2012). Como se halla en Pastor (2004) y Léon (1986) con respecto al ámbito de la educación no formal en el que se inscriben los museos y entre las formas de educación permanente, también aparece el medio sociocultural, esta vez relacionado con la educación popular, la preparación del ocio y la formación del ciudadano; esto último le otorga una responsabilidad mayúscula a las instituciones sociales y culturales en relación con la democracia y la ciudad, en lo que respecta a la instrucción y la formación de ciudadanía (Faure et ál., 1973).

En Colombia, hacia 1823 se crea el Museo de Historia Natural y Escuela de Minas, que se organizó bajo las gestiones de la comisión científica de Francisco Antonio Zea; antes de ser una institución abierta al público, lo que hoy se conoce como Museo Nacional fue un centro de estudios alrededor de su colección de objetos de ciencias naturales y funcionó como escuela de mineralogía (Rodríguez Prada, 2008, 2017). A finales del siglo XIX se afianza como insti- tución cultural, en el marco constitucional de 1886 y con la consolidación de disciplinas científicas que cimientan su discurso (Rodríguez, 1998).

En cuanto a su connivencia con lo ciudadano, una de las vertientes de investigación se orienta a la categoría de nación materializada en el Museo Nacional. Para Rodríguez, su fundación "difiere de las rutas convencionales que dieron origen a los museos en lo que hace referencia a su papel en la construcción pública del conocimiento, al establecimiento del poder gubernamental del estado moderno y a la formación del ciudadano" (1998, p. 79), pues, más que orientarse como proyecto cultural hacia su población interna, "fue planeado para producir una narrativa de nación que permitiera a los criollos ubicar la riqueza del territorio dentro de las nuevas taxonomías del poder" (pp. 85-86). Pérez (2010) considera que los museos americanos del siglo XIX son un espacio privilegiado para estudiar la manera como se configuró un orden simbólico, para sistematizar el territorio y la población en torno a la imagen de nación. A inicios del siglo XX, el entonces Ministerio de Instrucción Pública incentivaba sus usos públicos, como la atención al público escolar y la disponibilidad de sus objetos para conmemoraciones patrias, cívicas y militares, y en libros de historia por medio de reproducciones. Vanegas (2017), por su parte, lo considera como "una fuente de información invaluable para entender los procesos de formación del Estado Nación colombiano" (p. 30), así como de las transformaciones ideológicas sucedidas a lo largo del siglo pasado; como hipótesis, la autora asume que esta institución ha cambiado en relación con los marcos ideológicos constitucionales.

\section{Emergencia de lo educativo como función del museo}

Desde sus orígenes los museos cumplen con la tarea de "ilustrar" (Maceira, 2008, p. 48), en especial mediante objetos sensibles, ya sean auténticos o reproducciones, a la manera en que la didáctica comeniana postulaba el uso de las imágenes como estrategia para estimular los sentidos y facilitar el aprendizaje (Comenio, 1998). Sin embargo, su función educativa se le reconoce como expresión de una política museográfica moderna (Unesco, 1959) y es objeto de discusiones académicas y sociales con mayor intensidad a partir de la segunda mitad del siglo xx. Desde ese momento, las prácticas educativas en los museos se constituyen en uno de los propósitos de dicha institución, que se visibiliza hacia la década de los ochenta con la aparición de un área o departamento especializado como parte de su estructura y funcionamiento. A continuación 
se reseñará este proceso, que puede entenderse en tanto resultado de la intervención administrativa de la práctica gubernamental, en la que convergen la aplicación del conocimiento y el ejercicio del poder para crear nuevos niveles o departamentos de existencia social (Hunter, 1998).

La emergencia de la función educativa de los museos se considera fundamental pues, en palabras de López, significó su paso de contenedores de objetos patrimoniales a lugares de activación del patrimonio cultural para una comunidad específica (De Mello y López, 2013). En Latinoamérica, esta perspectiva se visibiliza en La Mesa Redonda de Santiago de Chile de 1972, como parte de los seminarios Unesco sobre el rol de los museos en la educación y su función didáctica, que antes habían tenido lugar en Brooklyn, 1952, Atenas, 1954, y Río de Janeiro, 1958. Al asociarse educación con escolarización, durante la década de los ochenta del siglo pasado, en Europa se discutió la polarización entre el museo-templo y el museo-escuela, siendo la crítica principal la escolarización del museo y la necesidad de reconocer otras audiencias (Franco-Avellaneda, 2013). En la década de los noventa, Carvalho observa que "en América Latina, casi siempre cuando promueven programas educativos en los Museos, son en su mayoría reproducciones de la pedagogía de las escuelas" (1996, p. 82); por lo que hace un llamado de atención para que los museos superen su posición pasiva como preservadores de objetos y contribuyan a la búsqueda de crecimiento, integración, educación y fortalecimiento de la identidad cultural, siendo necesario que dentro de su modernización se incluya la investigación y la decodificación de la información de manera que cualquiera pueda acceder a ella (Carvalho, 1996). Este tipo de preocupaciones aún persisten, al ser los grupos escolares el público más asiduo y la educación formal el mayor referente.

En el contexto nacional, ese enfoque explícitamente educativo ha tenido una trayectoria particular con respecto a las dinámicas de la región. La antropóloga Alicia Dussán de Reichel-Dolmatoff, ${ }^{2}$ fue la representante de Colombia en el mencionado encuentro de Chile; en ese entonces, para ella el museo de los setenta debía "orientarse de tal manera que presente a las nuevas generaciones toda la realidad de nuestro pasado, pero en forma de testimonio vivo y no como reliquia desvencijada", postulando la divulgación cultural como una de las principales funciones del "museo moderno" (citada en Escobar, 2017, p. 63). Sin embargo, mientras que en el Museo Nacional de Río de Janeiro el primer servicio educativo fue creado

2 En la década de los setenta, fue jefe de la División de Museos y Restauración del Instituto Colombiano de Cultura y presidenta de la Comisión Nacional del Consejo Internacional de Museos. en 1922 y en México los departamentos de educación en los museos iniciaron en los años sesenta del siglo $\mathrm{xx}$, en Colombia (aunque no hay mucha investigación al respecto), según López surgió a finales de los años setenta (De Mello y López, 2013).

Dicha unidad especializada como parte de la estructura administrativa aparece primero en el Museo de Arte Moderno de Bogotá liderado por la artista Beatriz González, luego en el Museo Nacional de Colombia bajo la dirección de Emma Araujo de Vallejo. En los años ochenta, se gestiona lo educativo en el desaparecido Museo del Siglo XIX, inspirado en los desarrollos teóricos y prácticos del Centro Pompidou alrededor de la activación cultural, y en el laboratorio de educación artística del Museo de Arte de la Universidad Nacional, dirigido por María Elena Bernal (De Mello y López, 2013). En tesis recientes se advierte esta necesidad de la construcción de las memorias de las prácticas museológicas en el país, en particular en el campo de la historia de la educación de los museos (Barragán, 2018). Las condiciones y características del museo para ser considerado como institución educativa y cultural han sido analizadas desde la acción educativa de los museos y del giro educativo en el discurso curatorial contemporáneo, como en el caso del Museo de Antioquia, para el cual se analiza el quién, a quién, qué, cómo, para qué y dónde de los procesos educativos museales (Soto et ál., 2013).

En la definición del 2007 que enuncia el Consejo Internacional de Museos (ICOM, por su nombre en inglés), el museo es

una institución sin fines lucrativos, permanente, al servicio de la sociedad y de su desarrollo, abierta al público, que adquiere, conserva, investiga, comunica y expone el patrimonio material e inmaterial de la humanidad y su medio ambiente con fines de educación, estudio y recreo. ${ }^{3}$ (ICOM, 2020; énfasis añadido)

En reconocimiento de los cambios en las dinámicas sociales y museísticas, la conferencia general del ICOM de septiembre del 2019 tuvo como eje revisar dicha definición, ante lo que no hubo consenso y el comité a cargo continúa con las reflexiones y discusiones al respecto. ${ }^{4}$ Uno de los cambios sustanciales que contemplaba la propuesta era la eliminación del término "educación", aspecto que ha generado controversia entre sectores de profesionales en museología. De acuerdo

3 Desde su creación en 1946, esta red de profesionales de museos y patrimonio ha emitido una definición que en esencia no ha tenido mayores variaciones.

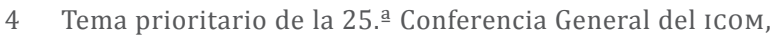
celebrada en Kioto (Japón) entre el 1 y el 7 de septiembre del 2019. Con una votación de 70,4 \%, se decidió aplazar la aprobación de la nueva propuesta, por lo que el debate sobre la redefinición sigue en curso (ICOM, 2020). 
con Daniel Castro Benítez, actual director del Museo Nacional de Colombia, si se trata de diálogo, interacción sensible e intercambio de saberes, la educación va a estar presente, sin necesidad que dicha palabra se encuentre incluida en la definición de museo. ${ }^{5}$

Además del análisis en el marco de la educación básica o en el campo de la educación informal, entre las líneas principales de la investigación educativa en el ámbito museal se encuentra el vínculo educación-difusión-entretenimiento, las interacciones que se dan en el museo, las estrategias de enseñanza-aprendizaje que se desarrollan en este, y la influencia del medio sociocultural en los museos, siendo frecuente el enfoque en los museos de ciencias - tanto por su oferta interactiva como por su relación más explícita con los planes de estudio de la educación formal como apoyo didáctico-y, en menor medida, en los museos de arte - por su relación con dinámicas de esparcimiento-; mientras que los museos antropológicos, de historia, arqueología y etnografía suelen estar al margen de esas reflexiones educativas (Maceira, 2008). La categoría de museos antropológicos como "aquellos que centran sus temas y colecciones en torno a la humanidad y su evolución histórica y cultural" (p. 50) operan a un nivel simbólico, razón por la cual se ha estudiado más su función en tanto dispositivos ideológicos que como escenarios educativos. Frente a ello, surge el cuestionamiento si dicha "ideologización" no implica un proceso educativo: "¿no serán estos valores que se reflejan en el discurso del museo un contenido educativo?, ¿no será el museo un dispositivo didáctico para aprender dichos contenidos?" (Maceira, 2008, pp. 50-51); para la autora, la respuesta es afirmativa.

Por ejemplo, en el desarrollo del concepto de museo arqueológico en Colombia, hacia la mitad del siglo xx ya se observa la interrelación del saber museológico y las pretensiones educativas. En particular, en las labores de Edith Jiménez y Blanca Ochoa, egresadas del Instituto Etnológico Nacional, que tuvieron una fuerte orientación hacia "la puesta en escena" del material arqueológico y etnográfico, para su exposición e "interpretación como evidencia del pasado prehispánico, fuente de la nacionalidad" (Echeverri, 2007, p. 79), así como a la elaboración de mapas y la publicación de las "Lecciones de prehistoria" que fueron divulgadas por maestros entre la población escolar (p. 83), todo ello imbuido en "la carga evolucionista de los estudios etnológicos de la época [donde] las culturas indígenas se revelaban

5 Intervención en el Curso de Formación y Voluntariado del Museo Nacional de Colombia (sesión del 19/10/2019). con una coherencia interna pero caduca para las condiciones de vida del presente" (Borja, citado en Echeverri, 2007, p. 81).

\section{El giro educativo en las prácticas curatoriales}

Los objetos que alberga un museo hacen parte de uno o más de los siguientes ámbitos museológicos: la colección (conjunto de objetos), la exhibición (muestra de esos objetos según su catalogación) y la exposición (disposición de objetos en el espacio para transmitir una idea, un concepto, un discurso). Esta última constituye el elemento bisagra que vincula al público con el campo de los saberes especializados que confluyen en el quehacer del museo. Una exposición es el producto de la labor de todas las áreas del museo, implica lineamientos de conservación, resultados de investigación, principios de diseño y estrategias de comunicación-educación. Desde mediados de la década de los noventa, y con mayor énfasis en el presente siglo, la curaduría o selección de objetos para comunicar narrativas ha tenido la influencia anglosajona del denominado "giro educativo" en el campo de las artes y la producción cultural, una "tendencia" que visibiliza las intersecciones entre arte y pedagogía que, en las últimas cinco décadas, han tenido lugar en los departamentos de educación de los museos (Acaso, 2011). En este sentido, la curaduría opera como la praxis educativa de concebir las exposiciones con el propósito de establecer una relación pedagógica-comunicativa con los públicos, a la vez que desde el área educativa se diseñan estrategias para activar las exposiciones mediante talleres, experiencias educativas o recorridos guiados con enfoque constructivista. Sin embargo, no deja de ser conflictiva la relación entre la acción educativa y el ejercicio curatorial, pues en la pretensión de hacer explícitos los procesos museales surge la preocupación de hasta qué punto es necesario "explicarlo todo".

La institucionalización de lo educativo como función del museo y su concreción administrativa no parecen resolver la cuestión educativa en las prácticas museales. Más allá de la formación de públicos como consumidores, cuya principal interacción con estos espacios es la contemplación estética, en el marco de la museología crítica se considera al arte como una forma de hacer, una herramienta didáctica orientada hacia la formación de ciudadanía crítica. En este sentido, aparece el perfil del artista educador (Acaso, 2011) y, en general, la pugna por la legitimidad académica del educador de museo. Fernández y Dias (2016) observan la emergencia de dicho perfil 
como resultado de cuestionar el distanciamiento, en la formación y la práctica, entre artistas y educadores del arte, como manifestación de una organización ideológica, social y económica. Los autores también advierten sobre el giro de la visualidad en la educación, cuyo punto de confluencia con el giro educativo en el arte es la educación en cultura visual, "porque hay una mayor preocupación por ir más allá de lo visible y participar de procesos ético estéticos en la construcción cultural y social del conocimiento" (Fernández y Dias, 2016, p. 9).

Además de denominaciones como curaduría o museografía educativa / didáctica / pedagógica, el giro educativo supone una postura crítica frente a la institucionalidad de las artes, de la academia, de la educación formal y, por ende, de los museos. Bajo esa expresión paraguas se cobija una diversidad de términos para referirse a lo que se hace desde esa orilla crítica, todo aquello que se pretende distinto a las formas de institucionalidad que son cuestionadas. Entre esos términos se encuentran etiquetas como mediación, pedagogía radical, autoaprendizaje o autoeducación, lo que también manifiesta "una cierta aversión hacia otros conceptos como educación o pedagogía, al considerar que pueden guardar alguna connotación cercana a lo escolar, al adoctrinamiento o a lo transmisivo" (Soria, 2015, p. 75). O'Neill y Wilson (2010) en la introducción a la obra compilatoria Curating and the educational turn caracterizan la educación como una categoría intensamente impugnada a lo largo de la historia, un terreno de conflicto social, político y económico que, como resultado de la discusión sobre sus contenidos y propósitos, ahora está siendo objeto de reingeniería como un sector al servicio de la economía y de la empresa privada. En este contexto, los autores afirman que la educación informal y las pedagogías culturales de los medios masivos proveen otros parámetros para lo educativo, que convergen en la reconfiguración del sistema educativo y en particular robustecen el debate acerca de los fines de la educación, campo en el que se ubica el giro educativo (O'Neill y Wilson, 2010).

Acerca de esa contienda conceptual en la que se enmarca la categoría educación, Dottrens y Mialaret (1972) advierten que esta es inherente a las relaciones humanas, mientras que la pedagogía como ciencia de la educación es de aparición tardía e intermitente. Los autores rastrean el origen de estos términos y ubican la aparición del primero hacia el siglo XIV y del segundo entre los siglos XV y XVI. La definición de Durkheim sería la simiente de la pedagogía en cuanto disciplina autónoma, "al considerar a la educación como una función social" y a la pedagogía como guía o "una 'teoría práctica' de la educación" (Dottrens y Mialaret, 1972, p. 31). Para comprender el lugar de la educación en procesos de humanización más amplios, Kron presenta los conceptos de enculturación y socialización. La enculturación abarca el medio de la existencia humana: la cultura, siendo también el medio en el que se mueve la educación, por lo que enculturación resulta ser el aprendizaje de la cultura. En dicho proceso el individuo aprende a adaptarse o a "actuar en su cultura 'al igual que todos los demás' " (personalidad) y a "ser como ningún otro" (identidad) (Kron, 1993, p. 8). La socialización, por su parte, es entendida como un proceso parcial de enculturación, pues se enfoca en el aprendizaje del orden moral, que es una clase especial de contenidos culturales: los sociales.

De esta manera, la enculturación y la socialización implican la noción de educación como mecanismo que tiene la sociedad para reproducirse y autopreservarse. "La educación como interacción simbólica es transmitida 'simbólicamente'" (Kron, 1993, p. 24) entre el maestro y el estudiante en la escuela, como momento y lugar especial, que demarca el ingreso del discípulo a su preparación para hacer parte de un proyecto de humanidad. La educación implica la enseñanza como práctica con propósito que, ya sea explícito, consiente, trascendente o no, sigue una serie de preceptos o lineamientos justificados desde un marco normativo, filosófico o científico de lo que se concibe ideal para los nuevos miembros de la comunidad. En este sentido, la acción de lo curatorial como parte de las prácticas museales pertenecería al ámbito de la enculturación; ahora, si pretende convertirse en un proceso eminentemente educativo, ¿qué, cómo y para qué se enseña? o ¿solo se espera que exista aprendizaje? Y, de ser así, ¿cuáles son las características de ese aprendizaje?

Desde la esfera cultural, el denominado giro educativo supone "una apuesta de la producción artística y comisarial ${ }^{6}$ por la generación de formatos, métodos, programas, procesos y procedimientos que se ocupan de la adopción de la educación como un tema desde un punto de vista crítico", a la vez que representa "una forma de legitimar al arte y el comisariado como praxis educativas críticas y radicales en sí mismas" (Soria, 2018, p. 23); no obstante, se reproducen los formatos usuales en la educación formal (clases magistrales, talleres, seminarios), así como la relación "jerárquica" entre los profesionales del museo y los públicos (2018, p. 24). Entonces, intentando dar respuesta a las preguntas planteadas, se trata de la educación como tema a ser cuestionado, pero que al ejecutarse como práctica se resuelve por la vía de la escolarización, que es la versión institucional objeto de crítica por parte

6 En España se utiliza el término comisariado y sus acepciones para referirse a las prácticas curatoriales. 
del giro educativo. Si la pretensión de dicha vertiente es la concepción de espacios como los museos en cuanto "nuevos escenarios educativos" (Serra y Rios, 2015, p. 129), esto podría converger en la concepción rousseauniana de medio educativo (Noguera, 2012, p. 148), donde opera la mediación del preceptor como agente que garantiza las condiciones o ambientes para el aprendizaje. Pero, si opera como un conjunto de prácticas que no contemplan la enseñanza, estaríamos hablando de "escenarios de aprendizaje"; es decir, de un aprendizaje por fuera de lo educativo.

Dado su carácter de concepto vacío, en principio el aprendizaje se valora como bueno y deseable sin que se definan sus contenidos y objetivos. Esto ha permitido que el lenguaje del aprendizaje permee todos los ámbitos, desde los cotidianos hasta los académicos, a través de su legitimización por medio de teorías focalizadas en el aprendiz, la crítica a formas autoritarias de aprendizaje, la masiva participación en diversas formas de aprendizaje - en su mayoría, de tipo no formal e informal-y el impacto individualizador de la política neoliberal en la educación (Biesta, 2017, p. 81). No obstante, el afán por erradicar el autoritarismo percibido en la mediación del maestro, está erosionando la definición misma de educación. En consecuencia, esta perspectiva supone profundas transformaciones en el método mediante el cual se pretenden lograr los propósitos de la escolarización; hago uso de este último término teniendo en cuenta que estamos tratando con algo diferente a la educación en sentido estricto, pero haciendo énfasis en que de alguna forma su ensamblaje institucional persiste. Así, el giro educativo, como crítica a la mercantilización neoliberal en el ámbito de la producción artística y cultural, puede convertirse en un producto más, dado el carácter fagocitador del sistema (Soria, 2018), ¿una moda? En palabras de Simons y Masschelein, "mientras lo social, las normas sociales y la socialización cumplieron un rol estratégico en anteriores regímenes sociales de gobierno; hoy inclusión, capital y aprendizaje parecen ser los componentes estratégicos" (2013, p. 97).

De la revisión conceptual realizada en este apartado, se puede plantear que el llamado giro educativo supone un viraje hacia el aprendizaje. Como se presentó en el recorrido histórico de la institución museal, el hito de su apertura al público manifestó su vocación por la enseñanza, que implica un fuerte vínculo social en el cual se pueden dar ciertos aprendizajes, es decir, se establece una relación educativa. Esta no surge con su declaración como función administrativa, pues es inmanente a sus intenciones de mostrar / exhibir / exponer cierto tipo de materialidades e ideas, de acuerdo con unos propósitos o en el marco de determinados saberes o disciplinas que, como en el caso de los museos antropológicos, se adscriben a ideologías de las que emanan referentes de identidad, ciudadanía, nacionalidad y cultura. Ahora, cuando el aprendizaje se convierte en el eje, en pro o en contra de la noción de educación, lo que se advierte es un afán por borrar el direccionamiento de la mirada con fines artísticos o científicos para dejarla al albedrío del espectador. La anterior es una hipótesis que puede ser leída en términos de la caída de los cimientos monolíticos de la modernidad, que a su vez ha horadado los esfuerzos por construir proyectos de colectivo y de una consonante idea de educación.

\section{Apropiación de los discursos sobre el aprendizaje}

Al analizar la noción de educación a partir de la cual se reflexiona sobre el quehacer de la institución museal, se hallan concepciones diversas que dan cuenta de una dispersión de los focos de investigación más que de una amplitud intencional en la definición del concepto. En diferentes ámbitos, Noguera y Parra identifican dos causas para ello: la proliferación de las "pedagogías contemporáneas", donde "suelen emplearse de manera no diferenciada los conceptos propios de la pedagogía, sin reconocer la tradición de pensamiento que en estos se inscribe", y la centralidad que ha cobrado el concepto de aprendizaje, en particular, desde un perspectiva que "instrumentaliza cuestiones educativas y formativas a la vez que diluye otras centrales para pensar el problema de lo humano como asunto de construcción o creación" (2015, p. 77).

Al respecto, Maceira considera la educación en términos amplios como "cualquier situación o práctica que derive en un proceso que genere la incorporación de elementos en la subjetividad del actor, es decir, que genere un aprendizaje", "más allá de que haya tenido un origen intencional o no" (2008, pp. 49-50; énfasis añadido). La concibe como un proceso multimodal e incorpora reflexiones integradas sobre el aprendizaje, la enseñanza, la formación, las interacciones sociales, etc. La autora reconoce como prácticas educativas dirigidas a los públicos del museo acciones y productos tan diferentes como: las tareas directas de las áreas educativas; las actividades paralelas como conferencias, talleres, cursos, entre otras; los materiales didácticos y las publicaciones; el cedulario y otros apoyos en sala, y las exhibiciones como "objeto cultural" y recurso para el aprendizaje. Por su parte, Alderoqui y Pedersoli (2012) identifican las exposiciones como una invención reciente que reivindica 
la función pedagógica del espacio museal y utilizan denominaciones como educación, comunicación, difusión, divulgación y museopedagogía para referirse al oficio de guiar en las salas de exposición, coordinar programas y departamentos de educación y realizar curaduría educativa.

De esta manera, se observa que las actuales pugnas conceptuales de lo educativo en el ámbito museal se dan en términos del discurso del aprendizaje. Desde su conceptualización inicial en el ámbito de la psicología, el aprendizaje es un proceso emocional además de intelectual y, en este sentido, el maestro actúa como condicionador emocional, al hacer atractivo el material y reforzar el comportamiento adecuado (Ardila, 1979). Así, los resultados del aprendizaje en los museos se consideran, "más que cognitivos, de corte actitudinal y motivacional hacia el autoaprendizaje" (Sánchez, 2013, p. 20). Se trata de una "noción del aprendizaje como un proceso de producción de sentido sobre el mundo, que es construido individual y socialmente a través de la experiencia e incluye cambios cognitivos, afectivos, de actitudes y comportamientos" (Falk et ál., citados por Grupo de investigación Maloka, 2018, p. 175).

Kron diferencia entre aprendizaje social (interacción pedagógica) y aprendizaje (organización interna). Como término central de la pedagogía, el aprendizaje es entendido como un cambio intencionado en las formas de comportamiento del individuo, un proceso interno que es inducido por eventos externos. Además afirma que, como se evidencia en la socialización, "los seres humanos aprenden durante toda su vida" (1993, p. 39), puesto que son constructores de realidad y buscadores de significados. Al considerar el aprendizaje social, aparecen "nuevas formas sociales de enseñanza", así como la "apertura de la escuela hacia la vida social en sí" (p. 26) pues "la escuela es una función social de la sociedad" (p. 31), en la cual se despliega la enseñanza como catalizadora de aprendizaje técnico y social. En contraste, para Biesta, la idea del aprendizaje permanente "trata ante todo del desarrollo del capital humano para así asegurar el crecimiento competitivo y económico" (2017, pp. 83-84). Por esta vía, el conocimiento convertido en capital adscribe el aprendizaje al ámbito de lo privado, responsabiliza al aprendiz de manejar y emplear dicho capital hacia una adaptación ética basada en la automovilización en la lógica del liberalismo avanzado (Simons y Masschelein, 2013, p. 94).

Al ubicarse en el lado del aprendizaje, la discusión por lo educativo se transforma, pues si el objeto educativo se proyecta en las áreas de la cualificación, la socialización y la subjetivación, los programas de aprendizaje permanente se enfoca en el progreso económico, el desarrollo y la realización personal, y en la inclusión, el entendimiento y la actividad democrática (Biesta, 2017). Los principios de adaptación y renovación resultan fundamentales para justificar la necesidad de aprendizaje en una sociedad en constante cambio, en una lógica de producción abstracta de capital humano. Esto significa una ruptura con respecto a la educación permanente como proyecto antecesor, que se orientaba por objetivos personales y democráticos (Biesta, 2017), así como la desvinculación del aprendizaje de su tradicional contexto institucional (la educación escolar) y de sus condiciones (la enseñanza) (Simons y Masschelein, 2013).

De manera que la institución museal ha transitado desde los ideales de la educación permanente a los del aprendizaje permanente, continuo o a lo largo de la vida. Esto significa cambios en la concepción del público al que orienta sus esfuerzos y que estos tengan otros propósitos, pues su foco pasó del colectivo al individuo, donde la categoría de "ciudadano" es el factor común, con sus consecuentes transformaciones. Los museos también se encuentran signados por las dinámicas económicas, como lo evidencia su adscripción al hoy denominado sector cultural, razón por la cual se ven en la necesidad de mantenerse vigentes $y$, si en un momento sus pretensiones educativas eran acercar al ciudadano a la cultura, ahora sus acciones parecen encaminarse a crear una versión de la cultura atractiva para el ciudadano.

\section{Entre la escolarización y la comunicación de masas: el lugar de la transmisión}

Si no se trata de educación en stricto sensu, ¿qué es lo que propician las prácticas museales? El museo contemporáneo en el ámbito educativo se ubica entre las prácticas escolarizadas y las estrategias de los medios de comunicación; es decir, debe promover la instrucción de los ciudadanos en el relato de la identidad nacional y a la vez hace parte de la economía local, por lo que está conminado a hacer uso del espectáculo para convocar fuerzas sociales (Narváez, 2019). En cuanto a la escolarización del museo, al concebir a la educación formal como su principal referente, en particular por la predominancia del código alfabético, los visitantes más asiduos y competentes en este tipo de espacios son los grupos de estudiantes, mientras que otros sectores de la ciudadanía se encuentran al margen.

En cuanto medio de comunicación, el museo puede ser considerado como un agente que produce relatos sobre la nación, en cualquiera de sus 
componentes Estado-instituciones, país-territorio, nación-población (Narváez, 2019); pero, a diferencia de otros medios, el museo ofrece otras posibilidades como "la materialidad del objeto y la experiencia sensible en el espacio real" (Núñez, 2007, p. 187), así como la recreación de "una sensación de estarahí frente a lo real auténtico" (Morales, 2010, p. 30). Con respecto a su incipiente apertura al público en el siglo XIX, para Pérez "tal vez el que su estrategia de comunicación no fuera exclusivamente letrada, permitía el acercamiento a un público más amplio del que tenían otros dispositivos culturales como los impresos" (2010, pp. 90-91). La tensión se encuentra entre el énfasis en la cultura alfabética y el régimen de la visualidad, en la cual, las prácticas escolarizadas son más afines con la primera y los medios de comunicación con el segundo. Más aún, si bien educación implica comunicación, las estrategias comunicativas no necesariamente suponen una intención educativa.

Ahora bien, al reconocer a los museos como lugares de memoria o, como sugiere el término "museal", espacios de memoria en uso (Morales, 2010), lo que se discute es su función como transmisores de referentes de memoria. En el marco de las industrias culturales y de la "pedagogía de masas", la comunicación ha entrado a ocupar el lugar de la transmisión. Esta oposición la presenta Deleuze como la era de las sociedades disciplinarias, en la que priman los vehículos de transmisión, versus nuestra sociedad de control, con la hegemonía de las redes de comunicación (citado en Debray, 2007). Si seguimos a Debray (2007), comunicar es el acto de "transportar una información en el espacio" y transmitir es el acto de "transportar una información en el tiempo"; por tanto, comunicar es una condición necesaria para transmitir, pero no lo es todo. Nos encontramos en el afán actual por la memoria colectiva, la protección y la transmisión de patrimonios y herencias a las nuevas generaciones; a ello responde la tendencia compulsiva de la musealización que, en buena medida, se materializa en una memoria pública, comercializada y mediática, que resulta insuficiente y se olvida mucho más fácil que la memoria vivida, la memoria activa (Alderoqui, 2004). ${ }^{7}$ Se trata de una espacialidad imperativa, con la consecuencia de una historicidad evasiva, la exigencia por la accesibilidad en detrimento de la memoria (Debray, 2007).

7 Existe otra versión de este artículo bajo el título "Pasajes al patrimonio: el derecho a la herencia", publicado en abril del 2009 por la Dirección de Bibliotecas, Archivos y Museos (Dibam) de Chile. En el presente texto se toma como referencia la paginación del texto del 2004, pero las citas son la adaptación entre las dos versiones para hacer énfasis en la transmisión de lo patrimonial.
Al reconocer este vínculo del museo con la memoria, frente a la cual operarían tanto lo comunicativo como lo educativo, es necesario reflexionar acerca de la idea de transmitir como tercer término y mecanismo en común, que cobra el sentido de 'atar lazos con el pasado', siendo a su vez una forma de "poner a disposición otros mundos posibles" (Fattore y Caldo, 2011, p. 9). Es la transmisión de memorias como compromiso social, "para que la identidad no quede atrapada en el mundo privado, para que la identidad se inscriba en forma pública y compartida, para poder ejercer el derecho a la herencia" (Alderoqui, 2004, p. 120). Deber de la memoria y derecho a la herencia que convierten al sujeto en ciudadano con su vinculación a una comunidad. Esto se enmarca en el carácter inacabado de nuestra especie que hace necesaria la invención de una segunda naturaleza, que propicie el paso al mundo social: primero hombre, después ser un ciudadano (Noguera, 2012).

La crítica a la noción de gobierno llevó a impugnar la idea de transmisión (Fattore y Caldo, 2011), una crisis que también es la crisis de las instituciones, las cuales padecen tres taras principales que son a su vez los fundamentos de toda institución: ser prescriptiva, exclusiva y desigual (Debray, 2007). Por ello se hace necesario, de acuerdo con Fattore y Caldo (2011), pensar en una transmisión en medio de "la paradoja de la educación", la cual tiene que ver simultáneamente con la continuidad y la discontinuidad. Para los autores, esto significa considerar un diálogo entre las generaciones que permita la conservación de las tradiciones, así como una articulación más abierta en la relación con los legados, sean hegemónicos o críticos. Candau (2006) considera que el museo amplía el marco temporal de la memoria y la identidad de los ciudadanos, esto es, su "capital de memoria" (p. 96), que es transmitido por las generaciones precedentes pero nunca está fosilizado, pues "es objeto de agregados, de supresiones y de actualizaciones que lo enriquecen permanentemente" (p. 111). Una apelación a la memoria activa, vivida. En palabras de Karol,

toda sociedad necesita transmitir su memoria y
pasado saliendo de la condena de la repetición para
provocar una memoria liberadora. Una memoria
que proteja de la repetición, que incorpore en su
transmisión la diferencia e interpretación de lo
heredado cargado de sentido propio. (citada en
Alderoqui, 2004, p. 120)

La clave para aproximarnos a esta sinergia entre lo cultural y lo educativo con respecto a los objetos patrimoniales, que no nos hablan por sí mismos, estaría en pensar la transmisión en términos de enseñar y aprender a mirar, en "la convicción de que la mirada 
necesita estar instruida", que "el código para mirar necesita ser transmitido", lo que "nos interroga sobre las acciones a desarrollar con las nuevas generaciones y con los que no saben" (Alderoqui, 2004, p. 117). Siguiendo a Alderoqui (2004), una de esas formas de interrogarnos es pensar en cómo transmitimos una forma de mirar que posibilite ver el aura de los objetos patrimoniales. Y, a continuación, sugiere una idea de transmisión alrededor de lo patrimonial que incluye la subjetividad en la dinámica de recepción:

Transmisión que es siempre una conversación entre la narrativa del que transmite y la narrativa del que recibe. La mirada necesita estar instruida para poder ser capaces de vivir la transferencia entre lo inanimado y nosotros y así poder sentir el aura de una cosa, es decir el poder que tienen algunos objetos de hacernos levantar los ojos, de conferirle la capacidad de levantar la mirada. (2004, pp. 124-125)

Se trata de una transmisión que se da por vías diferentes a las genéticas, como funciona con la herencia biológica; es entonces el traspaso generacional de elementos básicos y fundamentales de sentido y coherencia cultural. La experiencia de contemporaneidad y de unir lazos con el pasado sucede en la interacción con el patrimonio, en el acto de transmitir esa herencia que nos invita a hacer parte de una comunidad, a ser ciudadano. Al retomar este concepto se abre "la discusión por los procesos de transmisión de saberes y construcción de identidades desde el campo amplio de lo cultural" (Fattore, 2020). En atención a las diferentes tipologías de materialidades, saberes, prácticas y valores involucradas en este ámbito, aparece la idea de educación patrimonial, con relación a la cual Teixeira (2006) introduce la noción de "alfabetización cultural", que puede ser entendida en función del conocimiento necesario para identificar, valorar y en consecuente apropiarse del patrimonio en función de las manifestaciones de identidad de una ciudadanía cultural.

La transmisión es una de las relaciones entre los bienes y los ciudadanos sobre las que "opera" o "conecta" la mediación como práctica de la educación patrimonial, que fue antecedida por la noción y figura del guía en espacios turísticos y museos; asimismo, es el culmen de la secuencia conocer-comprender-valorar-cuidar-conservar-transmitir (Fontal e Ibáñez, 2015). Viñao (2010) advierte que la valoración implicada en la conservación y la consecuente transmisión de la memoria, tangible como patrimonio y herencia cultural, pasa por el qué, el cómo y quiénes; también hace énfasis en la importancia de su uso, ya sea nostálgico, memorialístico, didáctico o científico, así como en sus condiciones como mecanismo.

Todo cambio en los soportes y modos de conservar el conocimiento y de transmitirlo ha tenido históricamente repercusiones en la memoria social e individual, en la herencia cultural de los seres humanos, y en los modos de acercarse, de mirar y de interpretar la realidad con el fin de encontrarle algún sentido y desenvolverse en ella. (Viñao, 2010, p. 33)

Pero, más allá de cierto fetichismo de los objetos en la catalogación y preservación de originales para ordenar la memoria y organizar la herencia cultural, la orientación principal es la divulgación y el conocimiento, que incluso se puede realizar a partir de copias o reproducciones (Viñao, 2010).

En definitiva, ante el imperativo de enseñar que es constitutivo del museo, cuyas intenciones se debaten entre la educación y la comunicación, en sus formas de escolarización y de masas, se halla el lugar de la transmisión desde el ámbito de la cultura. Se trata del mecanismo que permite conservar, a la vez que transformar, los referentes para la identidad ciudadana que se anclan en los relatos de nación / colectivo / comunidad, ordenados y expuestos a partir de los registros de memoria custodiados por la institución museal, en particular de tipo antropológico.

\section{A manera de cierre: el museo como necesidad}

Las reflexiones hasta aquí compartidas intentan dar cuenta de las vertientes de lo educativo en la trayectoria de las prácticas museales, en particular desde su manifestación institucional. Sin embargo, al pensarlo como práctica cultural en términos generales, lo museal trasciende las fronteras de su contenedor para estar presente en las acciones y materializaciones de la memoria, tales como el patrimonio. La idea de museo hunde sus raíces en el proceso civilizatorio, con el Museion o recinto que recoge los conocimientos de la humanidad y la pinakothéke como lugar para albergar "tesoros" de los "cultos" que "poseían el privilegio de transmitir los conocimientos y la cultura" en la antigua Grecia (Varine-Bohan, 1979, p. 10).

La consolidación de la institución museal es resultado de la contingencia histórica, en el marco del proyecto de educación permanente para virar de modo progresivo a propuestas centradas en el aprendizaje, como la que se conoce de manera paradójica como giro educativo. No obstante, a la tríada museo-memoria-patrimonio es intrínseca la transmisión como mecanismo de orden cultural que garantiza el vínculo 
generacional y posibilita el lazo social, por medio de la transversalidad entre el presente, el pasado y el futuro como posibilidad. En algunos contextos se desarrolla de acuerdo con propuestas establecidas de educación patrimonial o como parte de la gestión del área educativa de los museos, pero ha estado aconteciendo por diferentes vías y su más contundente evidencia es todo el conjunto de lo que se reconoce como herencia cultural y las acciones que nos disponen como sus herederos.

\section{Referencias}

Acaso, M. (2011). Perspectivas: situación actual de la educación en los museos de artes visuales. Ariel; Fundación Telefónica.

Alderoqui, S. (2004). Pasajes a la ciudad: el derecho a la herencia. En G. Frigerioy G. Diker (comps.), La transmisión en las sociedades, las instituciones y los sujetos: un concepto de la educación en acción (pp. 117-126). Novedades Educativas.

Alderoqui, S. y Pedersoli, C. (2012). Educación en los museos: De los objetos a los visitantes. Paidós.

Ardila, R. (1979). Psicología del aprendizaje. Siglo XXI.

Barragán, J. R. (2018). Génesis de la creación del departamento especializado en mediación al interior de los museos en Colombia. Área educativa del Museo Nacional de Colombia un estudio de caso [tesis de maestría no publicada, Universidad Nacional de Colombia].

Biesta, G. J. (2017). Aprendizaje. En El bello riesgo de educar. Cada acto educativo es singular y abierto a lo imprevisto (pp. 77-95). Ediciones SM.

Candau, J. (2006). Antropología de la memoria. Ediciones Nueva Visión.

Carvalho, I. (1996). La educación en los museos en América Latina. Revista Museo, 7, 81-84.

Comenio, J. A. (1998). Didáctica magna (8. ${ }^{\mathrm{a}}$ ed.). Porrúa.

Consejo Internacional de Museos (Iсом). (2020). Definición de museo. La creación de una nueva definición de museo -la columna vertebral del Iсом. https:// icom.museum/es/recursos/normas-y-directrices/ definicion-del-museo/

De Mello, C. y López, W. A. (2013, 27 de marzo). Pedagogía en museos [episodio podcast]. http://unradio.unal.edu. co/nc/categoria/cat/museos-en-vivo.html

Debray, R. (2007). Transmitir más, comunicar menos. A Parte Rei, 50, 1-13.
Dottrens, R. y Mialaret, G. (1972). El desarrollo de las ciencias pedagógicas y su estado actual. I. Educación y pedagogía: A- Definiciones clásicas. En F. Best et ál. (eds.), Introducción a la pedagogía (pp. 25-35). Oikos-Tau.

Echeverri, M. (2007). Antropólogas pioneras y nacionalismo liberal en Colombia, 1941-1949. Revista Colombiana de Antropología, 43, 61-90.

Escobar, A. C. (2017). Narrativas en disputa: El Museo Nacional de Colombia en la gestión de Emma Araujo de Vallejo (1975-1982) [tesis de maestría no publicada, Universidad Federal de Rio Grande del Sur].

Fattore, N. (2020). La pedagogía como registro. Reflexiones a partir del diálogo entre estética, pedagogía y transmisión. Pedagogía y Saberes, 53, 41-51. https://doi. org/10.17227/pys.num53-10693

Fattore, N. y Caldo, P. (2011). Transmisión: una palabra clave para repensar el vínculo pedagogía, política y sociedad. VIII Encuentro de Cátedras de Pedagogía de Universidades Nacionales Argentinas (pp. 1-13). La Plata.

Faure, E., Herrera, F., Kaddoura, A.-R., Lopes, H., Petrovski, A. V., Majid, R.y Champion, F. (1973). Aprender a ser. Alianza.

Fernández, T.y Dias, B. (2016). Aguas turbulentas: el encuentro entre el giro educativo en el arte y el giro de la visualidad en la educación. Artnodes, 17, 6-14. https://doi.org/10.7238/a.v0i17.2958

Fontal, O. e Ibáñez, A. (2015). Estrategias e instrumentos para la educación patrimonial en España. Educatio Siglo XXI, 33(1), 15-32. https://doi.org//10.6018/j/222481

Franco-Avellaneda, M. (2013). Educación en museos: artefactos, conocimiento y sociedad. En C. Aguirre, El museo y la escuela. Conversaciones de complemento (pp. 35-48). Parque Explora.

Grupo de investigación Maloka. (2018). Acercar las fronteras entre el museo y la escuela como escenarios educomunicativos. Nómadas, 49, 173-187. https://doi. org/10.30578/nomadas.n49a10

Hunter, I. (1998). Repensar la escuela. Subjetividad, burocracia y crítica. Ediciones Pomares-Corredor.

Kron, F. W. (1993). Términos básicos de la pedagogía. En W. Küper, Pedagogía general (pp. 5-59). Abya-Yala.

Léon, A. (1986). La educación permanente. Evolución de los conceptos y de las funciones. En A. Léon, M. et ál., Formación continua y educación permanente (pp. 19-49). Oikos-Tau. 
Maceira, L. (2008). Los museos en la educación de personas jóvenes y adultas. Revista Interamericana de Educación de Adultos, 30(1), 47-76. http://www.redalyc.org/articulo.oa? id $=457545098002$

Morales, L. G. (2010). La escritura-objeto en los museos de historia. Intervención, 1(1), 30-38.

Moreno, N. (2016). Intersticios entre prácticas artísticas, pedagógicas y curatoriales en Colombia. Errata, 16. http://revistaerrata.gov.co

Narváez, A. (2019). Educación mediática, institución cultural y nación. Entre el púlpito, el museo e internet. Pedagogía y Saberes, 50, 159-172.

Noguera, C. E. (2012). El gobierno pedagógico. Del arte de educar a las tradiciones pedagógicas. Bogotá: Siglo del Hombre.

Noguera, C. E. y Parra, G. A. (2015). Pedagogización de la sociedad y crisis de la educación. Elementos para una crítica de la(s) crítica(s). Pedagogía y Saberes, 43, 69-78. https://doi.org/10.17227/01212494.43pys69.78

Núñez, A. (2007). El museo como espacio de mediación: el lenguaje de la exposición museal. Universitas Humanís tica, 63, 181-199.

O'Neill, P. y Wilson, M. (2010). Curating and the educational turn. Open Editions.

Pastor, M. I. (2004). Pedagogía museística. Nuevas perspectivas y tendencias actuales. Ariel.

Pérez, A. C. (2010). Hacer visible, hacerse visibles: la nación representada en las colecciones del museo. Colombia, 1880-1912. Memoria y Sociedad, 14(28), 85-106.

Rodríguez Prada, M. P. (2017). Colecciones y saberes: construcción patrimonial del Museo Nacional de Colombia y de la Escuela de Minas (1823-1830). Apuntes, 30(2), 126-147. https://doi.org/10.11144/Javeriana.apc30-2. $\operatorname{cscp}$

Rodríguez Prada, M. P. (2008). Origen de la institución museal en Colombia: entidad científica para el desarrollo y el progreso. Cuadernos de Curaduría, 6. http:// www.museonacional.gov.co/cuadernos.html

Rodríguez, V. M. (1998). La fundación del Museo Nacional de Colombia. Ambivalencias en la narración de la nación colombiana moderna. Nómadas, 5(1), 76-87.

Sánchez, M. D. (2013). La relación Museo-Escuela: tres décadas de investigación educativa. En C. Aguirre, El museo y la escuela. Conversaciones de complemento (pp. 11-22). Parque Explora.

Serra, M. S. y Rios, G. A. (2015). Las ciudades como territorio de la educación integral. Educação em Revista, 31(4), 121-134. http://doi.org/10.1590/0102-4698151372
Simons, M. y Masschelein, J. (2013). "Se nos hace creer que se trata de nuestra libertad": notas sobre la ironía del dispositivo de aprendizaje. Pedagogía y Saberes, 38, 93-102.

Soria, F. (2018). El giro educativo en las artes y el comisariado. Riesgos y oportunidades a la hora de generar procesos de transmisión institucional. Pulso. Revista de educación, 41, 21-33.

Soria, F. (2015). El giro educativo y su relación con las políticas institucionales de tres museos y centros de arte del contexto español. Universitat de Barcelona.

Soto, C. A., Angulo, F., Runge, A. K. y Rendón, M. A. (2013). Pensar la institución museística en términos de institución educativa y cultural, el caso del Museo de Antioquia. Revista Latinoamericana de Ciencias Sociales, Niñez y Juventud, 11(2), 819-833. http://doi.org/10.11600/1 692715x.11224180213

Teixeira, S. (2006). Educación patrimonial: alfabetización cultural para la ciudadanía. Estudios pedagógicos, 32(2), 133-145.

Unesco. (1959). Resumen de los informes: Chile. Museum International, XII(3), XXXIX-XL.

Vanegas, L. X. (2017). El Museo Nacional de Colombia y las representaciones de lo nacional: reflexiones sobre la paz y la globalización. Revista de Ciencias Sociales Universidad de Costa Rica, IV, 29-44.

Varine-Bohan, H. (1979). Los museos en el mundo. Salvat Editores.

Viñao, A. (2010). Memoria, patrimonio y educación. Educatio Siglo XXI, 28(2), 17-42. 